\title{
Internal structures of fault zones in the PriOlKhONIE AND EVOLUTION OF THE STATE OF STRESSES OF THE UPPER CRUST OF THE BAIKAL RIFT
}

\section{A. V. Cheremnykh}

Institute of the Earth's Crust, Siberian Branch of RAS, 664033, Irkutsk, Lermontov street, 128, Russia

Abstract: The Priolkhonie is a tectonic block located in the central part of the Baikalsky Ridge; it was shifted in the Cenozoic, yet remains above the water level of Lake Baikal. In view of its unique positioning and abundant rock outcropped sites, especially at shorelines, we conducted studies of internal structures of the main fault zones and reconstructed the states of stresses associated with formation of such zones.

The studies were conducted along the profile which goes across the Priolkhonie, from the Primorsky Ridge near the Sarma River to the Tutai Bay in the Olkhonskie Vorota Strait (Fig. 1). Detailed cross-sections are constructed to characterize the internal structures of the fault zones striking of the NE-strike, that are located in highly outcropped sites at the shorelines of the Mukhor, Kurkut and other bays.

The state of stresses in the fault zones and their vicinities are studied (Fig. 2, 3) by the structural paragenesis analysis of the second-rank ruptures and fracturing nearby the fault planes [Seminsky, Burzunova, 2007]. As possible, the obtained results are checked by the kinematic method which provides for reconstruction of the main axes of normal stresses [Parfenov, 1984].

Most of the fault zones are complicated in structure (Fig. 4-7): the fault is typically represented by alternating areas, wherein tectonites of the main fault are developed, and areas of high fracturing at the periphery of the fault zone. With this approach, the fault zone's boundaries are defined by quantitative indicators of tectonic fracturing, being abundantly manifested in the rocks.

Our solutions give evidence that extension (Fig. 8) and shear fractures are abundant in the area under study, while fractures caused by compression are revealed quite rarely. The faults of the above mentioned morpho-genetic types have been revealed in the studied outcrops in the following ratio: $55 \%, 27 \%, 10 \%$, and $8 \%$. Our study gives grounds to conclude that the state of stresses of the upper crust in this territory developed from compression, via shear, to extension. It is also evidenced that strike-slip faults with the left-lateral component and normal faults developed in the Cenozoic.

Keywords: Baikal rift, fault zones, state of stresses, tectonic fracturing.

Recommended by V.A. San'kov 28 June 2010

Cheremnykh A.V. Internal structures of fault zones in the Priolkhonie and evolution of the state of stresses of the upper crust of the Baikal rift // Geodynamics \& Tectonophysics. 2010. V. 1. № 3. P. 273-284.

\section{ВНУТРЕННЯЯ СТРУКТУРА РАЗЛОМНЫХ ЗОН ПРИОЛЬХОНЬЯ И ЭВОЛЮЦИЯ НАПРЯЖЕННОГО СОСТОЯНИЯ ВЕРХНЕЙ КОРЫ БАЙКАЛЬСКОГО РИФТА}

\section{А. В. Черемных}

Институт земной коры СО РАН, 664033, Иркутск, ул. Лермонтова, 128, Россия

Аннотация: Приольхонье - тектонический блок, расположенный в центральной части Байкальского рифта, сброшенный в кайнозойское время относительно Приморского хребта, но оставшийся не затопленным водами озера Байкал. Его уникальное положение и хорошая обнаженность горных пород, особенно в прибрежной части, 
позволили изучить внутреннюю структуру основных разломных зон и восстановить напряженное состояние, в котором были сформированы последние.

Работы проведены по профилю, пересекающему Приольхонье поперек, от Приморского хребта в районе р. Сарма до Тутайского залива пролива Ольхонские Ворота (рис. 1). Это позволило построить детальные разрезы, характеризующие внутреннюю структуру разломных зон северо-восточного простирания в местах наиболее хорошей обнаженности - на побережье заливов Мухор, Куркут и др.

Напряженное состояние в зонах разломов и их окрестностях было исследовано (рис. 2, 3) на основе структурно-парагенетического анализа разрывов второго порядка и трещиноватости вблизи разломных сместителей [Seminsky, Burzunova, 2007]. По возможности, результаты проверялись с помощью кинематического метода восстановления осей главных нормальных напряжений [Парфенов, 1984].

Структура большинства разломных зон имеет сложное строение (рис. 4-7): разлом обычно представлен чередующимися областями развития тектонитов основного сместителя и участками с повышенной трещиноватостью на периферии зоны. При таком тектонофизическом понимании зоны разлома ее границы выделялись с применением количественных показателей широко распространенной в горных породах тектонической трещиноватости.

Полученные решения свидетельствуют о широком распространении обстановок растяжения и сдвига (рис. 8) при весьма редком наблюдении трещиноватости, образовавшейся при сжатии. В этих обстановках разломы северо-восточного простирания развивались как сбросы, левосторонние сдвиги, взбросы и сдвиги с правосторонней компонентой смещения. Разломы перечисленных морфогенетических типов встречаются в обнажениях в следующих соотношениях: 55 \%, 27 \%, 10 \% и 8 \%. Проведенное исследование свидетельствует, что на данной территории происходила эволюция напряженного состояния верхней коры от сжатия, через сдвиговое поле, к растяжению. При этом сдвиги с левосторонней компонентой смещения и сбросы развивались в кайнозойское время.

Ключевые слова: Байкальский рифт, разломные зоны, напряженное состояние, тектоническая трещиноватость.

\section{ВведенИЕ}

Приольхонье расположено в центральной части Байкальского рифта и является блоком, сброшенным по Приморскому разлому относительно северозападного плеча рифта. Он остался не затопленным водами озера Байкал, что в совокупности с хорошей обнаженностью (особенно в прибрежной части) позволяет детально изучить внутреннюю структуру разноранговых разломных зон и восстановить напряженное состояние, в котором происходило формирование разломов и деформация слабонарушенных блоков.

Многие разломы региона образовались задолго до кайнозоя и неоднократно активизировались на различных этапах тектонического развития Приольхонья [Плешанов, Чернов, 1971; Семинский, 2003; u дp.]. Для Прибайкалья известны отличающиеся по напряженно-деформированному состоянию этапы, среди которых наиболее проявлены палеозойский, характеризующийся сжатием, ориентированным СЗ-ЮВ [Александров, 1990; Fedorovsky, 1997], и кайнозойские: сдвиговое поле напряжений раннеорогенной стадии развития территории и растяжение, ориентированное СЗ-ЮВ, характерное для позднеорогенной стадии [San'kov et al., 1997; Парфеевец и др., 2002]. В последнее время появились более детальные модели мезокайнозойского цикла деформации Байкальской рифтовой зоны [Петров и др., 2008] и пространственно-временного развития впадин Прибайкалья в мезозое-кайнозое [Лунина и др., 2009]. Эти модели, отражающие несколько этапов региональных полей напряжений, имеют существенные различия и, несомненно, требуют уточнения. Хорошо изученным является лишь напряженное состояние СЗ-ЮВ растяжения, которое установлено для современного этапа развития
Байкальского рифрта по механизмам очагов землетрясений [Мишарина, Солоненко, 1977; Mel'nikova, Radziminovich, 2007; u dp.]. Оно также является наиболее распространенным при восстановлении палеонапряжений геолого-структурными и тектонофизическими методами [San'kov at al., 1997; Парфеевец и др., 2002; Cheremnykh, 2006; Петров и др., 2008; Лунина и др., 2009; и др.]. Дискуссионным остается вопрос об эволюции напряженного состояния земной коры Прибайкалья. Однако его изучение невозможно без детальных исследований в зонах разломов и в слабонарушенных блоках.

\section{ОБЪЕКТЫ ИССЛЕДОВАНИЯ И МЕТОДИКА РАБОТ}

Ранее были изучены специфические особенности напряженного состояния верхней коры восточного побережья озера Байкал, связанные с ее разломно-блоковой структурой, и показана пространственная составляющая распределения полей напряжений [Cheremnykh, 2006]. Северо-западное крыло Байкальского рифта, к которому относится Приольхонская краевая ступень [Мац и др., 2001], характеризуется сводом, осложненным серией сбросов. Наиболее доступная для изучения область Приольхонья примыкает к побережью заливов Мухор, Куркут, Базарная Губа пролива Ольхонские ворота, где широко распространены разломы СВ простирания, наиболее характерные для Байкальского рифта. Разрывы СЗ ориентации встречаются здесь значительно реже, что способствует существенному ослаблению их искажающего влияния при исследовании напряженного состояния вблизи основных рифтообразующих разломов. Именно в этой части Приольхонья (рис. 1) были проведены исследования, направленные на изучение внутренней структуры зон разломов и напряженного состояния 


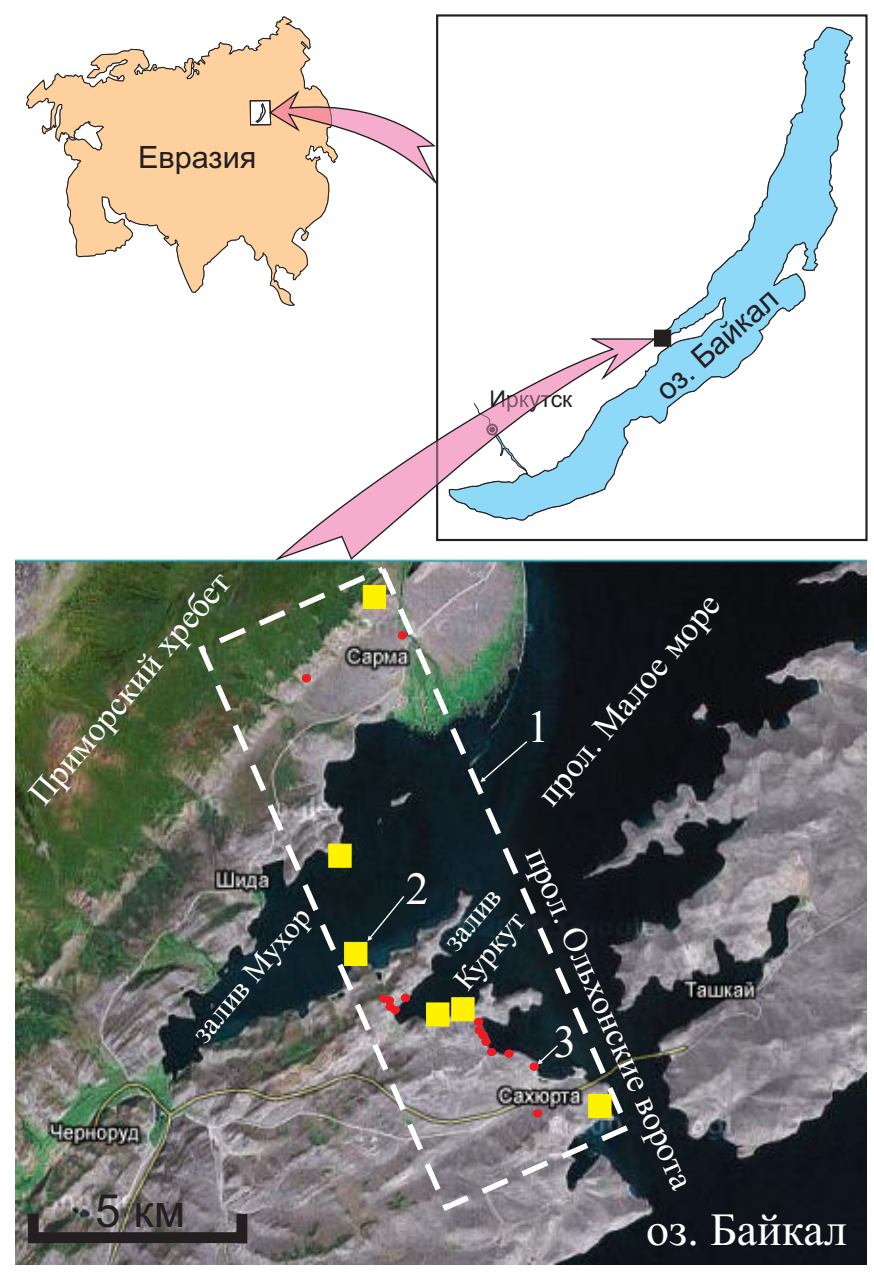

Рис. 1. Район исследований.

1 - участок сбора фактического материала; 2 - площади детальных комплексных исследований; 3 - точки геолого-структурных наблюдений.

Fig. 1. Region under study.

1 - data collection site; 2 - areas of detailed comprehensive studies;

3 - points of geological and structural observations.

верхней коры вблизи них, что позволило рассмотреть изменение полей напряжений не только в пространстве, но и во времени.

Структурно-геологические и тектонофизические исследования, результаты которых представлены в данной работе, проводились параллельно с геоморфологическими и геофизическими работами и являются частью большого комплекса наблюдений внутренней структуры разломных зон [Семинский и др., 2008]. В пределах дизъюнктивов, выявленных ранее [Семинский и др., 2005], проведены детальные исследования, которые сопровождались измерением элементов залегания разрывов и их мощности, установлением направления подвижки по смещению маркеров и штрихам скольжения на поверхностях трещин, характеристикой тектонитов, а также сбором количественной информации по трещиноватости горных пород (ориентировка и плотность трещин). Кроме того, на определенных интервалах зоны разлома производились массовые замеры ориентации разрывов и трещин, обработка которых осуществлена в лаборатории тектонофизики Института земной коры СО РАН с применением оригинальной программы «Структура». В программе реализованы операции по построению проекций структурных элементов на стереометрических сетках, а также некоторые методы реконструкции осей главных нормальных напряжений [Гзовский, 1963; Парфенов, 1984] и вектора смещения по разлому [Данилович, 1961].

Остановимся подробнее на особенностях оконтуривания разломных зон и выявления трещиноватости, связанной с формированием дизъюнктивов. Известно, что разлом представляет собой достаточно широкую сложнопостроенную зону, в которой, помимо основного сместителя, имеются разрывы второго и последующих порядков до самых мелких макроструктур - трещин [Шерман, 1977; Семинский, 2003]. Выявление структур разных порядков в зоне крупного разлома часто затруднено из-за интенсивной тектонической переработки горных пород. Однако собственно трещиноватость, присутствующая в каждом обнажении горных пород, позволяет решать эту задачу. Так, при исследовании внутренней структуры Приморского разлома была показана возможность применения количественных характеристик трещиноватости для оконтуривания областей влияния разноранговых частных разрывов в зоне крупного дизъюнктива [Lunina et al., 2002].

Детальные исследования внутренней структуры зон разломов северо-восточной ориентировки проводились на профиле С3 простирания, в связи с чем трещиноватость изучалась на стенках обнажений с практически одинаковой экспозицией. Кроме того, сопоставление результатов различных способов подсчета плотности трещиноватости на тестовых участках, в пределах профиля, показало их принципиальную сходимость. Поэтому в наших исследованиях был принят наиболее простой показатель - количество трещин на стенке обнажения площадью $1 \mathrm{~m}^{2}$, величина которого в зонах разломов имеет значение более $22 \mathrm{Tp} / \mathrm{m}^{2}$ [Lunina et al., 2002].

Следует отметить, что количество трещин в разломных зонах зависит от множества факторов: состава пород, их структурных особенностей, стадии развития разлома, нарушенности горных пород трещинами нетектонической природы и др. Кроме того, отнести конкретные трещины к формированию наблюдаемого в обнажении разлома весьма трудно, но возможно с помощью парагенетического анализа разрывов второго порядка и трещиноватости вблизи разломных сместителей [Seminsky, Burzunova, 2007]. Применение этого метода требует практических навыков и не всегда позволяет получить однозначный вывод о кинематическом типе разлома, особенно для Приольхонья, в связи с высокой тектонической переработкой горных пород региона в различные периоды геологической истории. Однако метод дает возможность расшифровать даже сложнодислоцированную «хаотическую» трещиноватость вблизи сместителей разломов и выявить разноранговые сопряженные системы тре- 

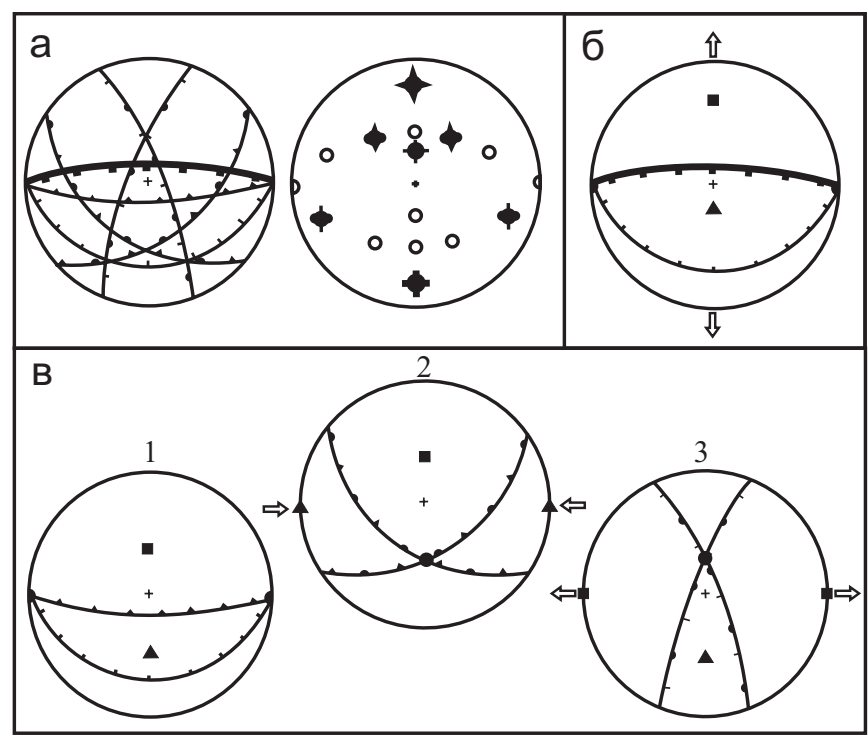

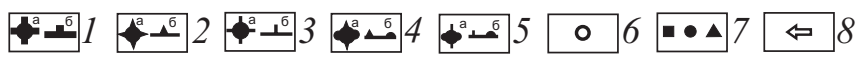

Рис. 2. Эталонный парагенезис разрывов 2-го порядка и соответствующих им систем трещин в зоне сброса (a) (по [Семинский, 2003]) и реконструкции осей главных нормальных напряжений первого (б) и второго порядка (в).

Парагенезис представлен на круговых диаграммах (верхняя полусфера, сетка Вульфа) в плоскостях и полюсах для наиболее распространенного в природе случая сложного скалывания (угол между сместителем разлома и осью сжатия $-55^{\circ}$; угол скалывания $-30^{\circ}$ ), что позволяет использовать его для интерпретации массовых замеров трещинных сетей [Seminsky, Burzunova, 2007]. 1 - полюса (а) и плоскости (б) главного сместителя 1-го порядка (Y); 2 - полюса (а) и плоскости (б) взбросового сместителя 2-го порядка (R); 3 - полюса (а) и плоскости (б) сбросового сместителя 2-го порядка (R'); 4 - полюса (а) и плоскости (б) взбрососдвигов 2-го порядка; 5 - полюса (а) и плоскости (б) сбрососдвигов 2-го порядка; 6 - положение полюса второстепенной и дополнительной систем трещин; 7 - оси главных нормальных напряжений (квадрат $-\sigma_{1}$; кружок $-\sigma_{2}$; треугольник $\left.-\sigma_{3}\right) ; 8-$ направление действия сил субгоризонтальной ориентации $\left(<30^{\circ}\right)$.

Fig. 2. Standard paragenesis of the second-rank fractures and corresponding fracture systems in the normal fault zone (a), according to [Семинский, 2003]. Reconstruction of the axes of the main normal stresses of the first (б) and second (B) ranks.

The paragenesis shown in circular diagrams (upper semi-sphere, Wolf net) refers to complicated shearing which is most typical for natural cases (the angle between the fault plane and the compression axis is $55^{\circ}$; shearing angle is $30^{\circ}$ ) and thus can be used for interpreting mass measurements of fracture patterns [Seminsky, Burzunova, 2007].

1 - poles (a) and planes (б) of the main fault of the first rank (Y); 2 - poles (a) and planes (б) of the second-rank overthrust (R); 3 poles (a) and planes (б) of the second-rank normal fault (R'); 4 poles (a) and planes (б) of the second-rank strike slip faults with overthrust component; 5 - poles (a) and planes (б) of the secondrank strike slip faults with normal component; 6 - position of the pole of the second-rank and additional systems of fractures; 7 - axes of the main normal stresses (box $-\sigma_{1}$; circle $-\sigma_{2}$; triangle $-\sigma_{3}$ ); 8 - subhorizontal force directions $\left(<30^{\circ}\right)$.

щин скола, необходимые для восстановления ориентировки осей напряжений.

Рассмотрим структурный парагенезис зоны крутопадающего сброса (рис. 2), который состоит из магистрального сместителя 1-го порядка, сколов первой серии (разрывы 2-го порядка - сброс и взброс), сколов второй серии (взбросо-сдвиги 2-го порядка), сколов третьей серии (сбросо-сдвиги 2-го порядка) и трещиноватости второстепенной и дополнительной систем (рис. 2, а). Он образуется при изменении напряженно-деформированного состояния в зоне разлома за счет формирования сопряженных сколов нескольких серий, из-за чего при близких величинах напряжений происходит частичное снятие напряжений по определенным направлениям и, соответственно, переиндексанция осей (рис. 2, в). Следовательно, при выявлении парагенезиса возможна реконструкция напряжений нескольких рангов. Во-первых, это напряжения, в результате которых образуется трещиноватость, вовторых, поля напряжений, связанные с взаимодействием разрывов второго порядка (рис. 2, в) и, втретьих, напряженное состояние, в котором формируется собственно магистральный сместитель (рис. 2, б). Таким образом, данный методический подход позволяет анализировать приразломные, сложные по строению, сети трещин и несет в себе новые возможности изучения разноранговых полей напряжений. Нами этот метод применялся в следующем варианте.

Для каждого массового замера трещиноватости и мелких разрывов строилась круговая диаграмма (верхняя полусфера), на которой в изолиниях отображалась плотность структурных элементов. Это позволило выявить максимумы трещиноватости и разрывов второго порядка. Затем на диаграмму последовательно накладывались палетки с эталонными парагенезисами структурных элементов: сброса, взброса, левого и правого сдвигов (рис. 3). Палетки были составлены на основе анализа большого фактического материала по трещиноватости горных пород вблизи разломных плоскостей и построений на круговых диаграммах идеализированных сочетаний парагенезисов трещин, образующихся в зонах разломов при транспрессивном скалывании [Семинский, 2003]. Далее проводился комплексный анализ, включающий сопоставление с каждым эталонным парагенезисом всех имеющихся для обнажения данных: характера подвижек, установленных по зеркалам скольжения или восстановленных методом поясов [Данилович, 1961]; координат разрывов, зафиксированных непосредственно на обнажениях горных пород, смещений маркеров и т.п. Анализ позволил установить морфогенетические типы разломов и положения сопряженных сколов, что необходимо для восстановления напряженного состояния, при котором сфрормировалась трещиноватость горной породы на конкретном участке обнажения. Дальнейшее восстановление ориентации осей главных нормальных напряжений по сопряженным сколам произведено согласно методике, детально изложенной в работе [Гзовский, 1963]. При этом следует отметить, что изучалось напряженное состояние, при котором формировались сколы первой серии ( $\mathrm{R}$ и $\mathrm{R}^{\prime}$ ) или основной сместитель разлома $(\mathrm{Y})$. Если на поверхностях трещин наблюдались штрихи или борозды скольжения, то результаты парагенетического анализа проверялись с помощью кинематического метода восстановления осей главных 

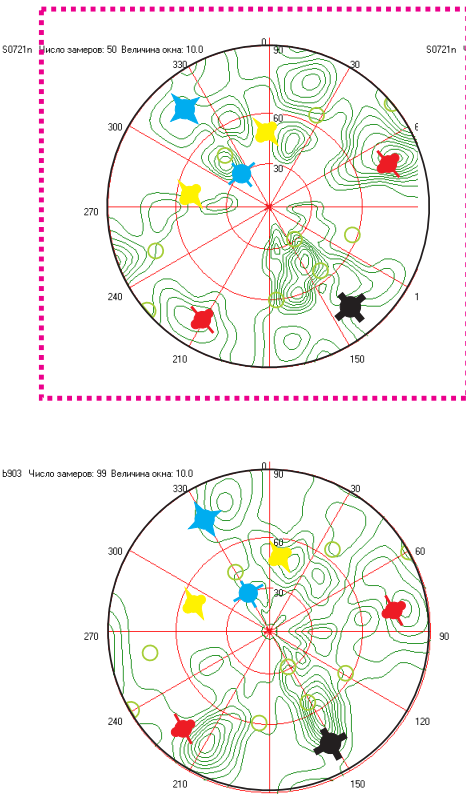

$\sigma$
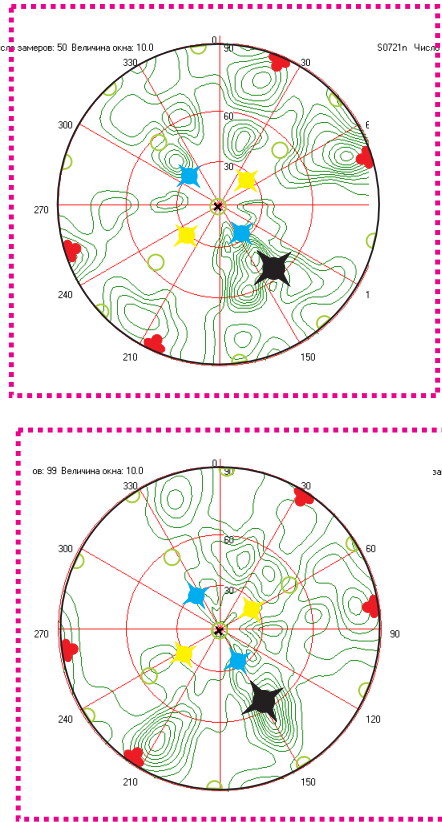

B
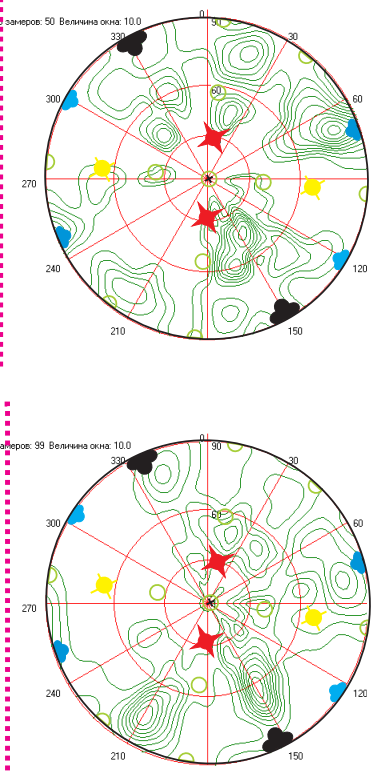

2
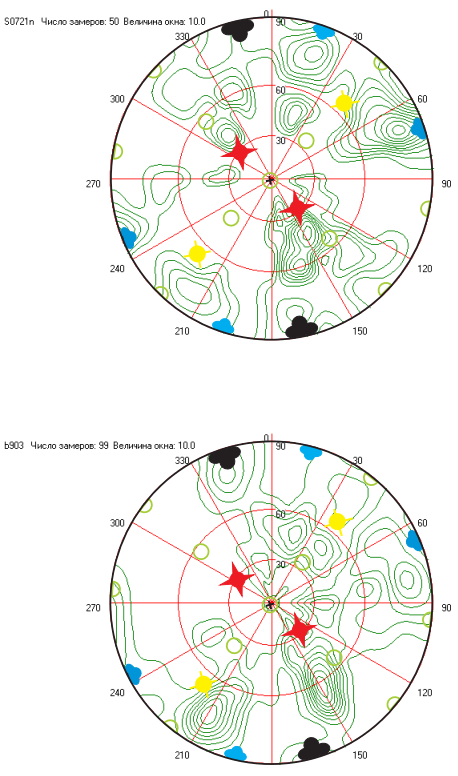
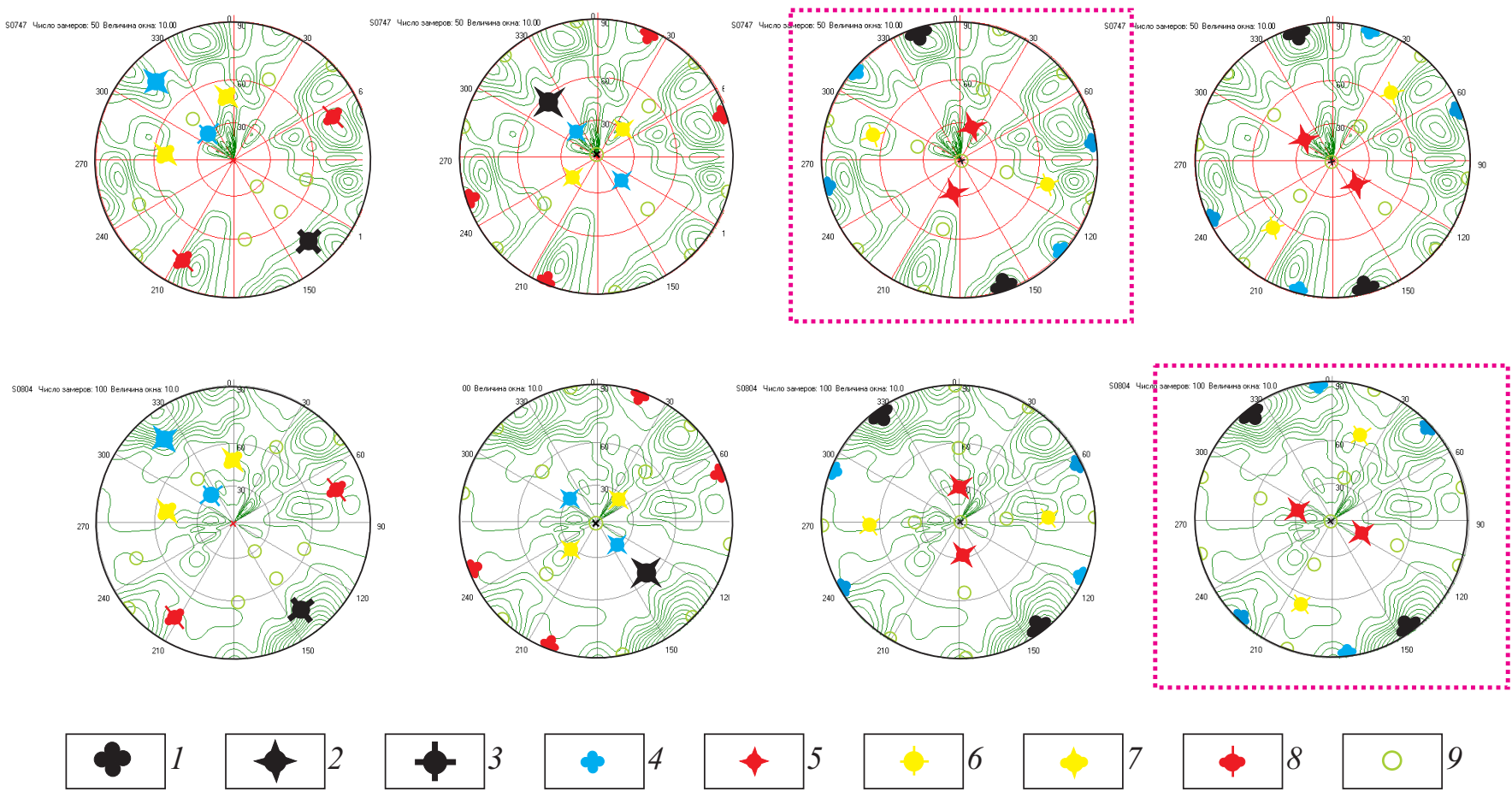

Рис. 3. Пример сопоставления диаграмм с эталонными парагенезисами разрывов 2-го порядка и трещиноватости в зонах сброса (а), взброса (б), левого (в) и правого (2) сдвига.

Полюсы главных сместителей 1-го порядка: 1 - сдвигового, 2 - надвигового (взбросового), 3 - сбросового типов; полюсы разрывов 2-го порядка (цветом отображены разрывы разных серий): 4 - сдвигов, 5 - надвигов (взбросов), 6 - сбросов, 7 - взбросо-сдвигов, 8 - сбросо-сдвигов; 9 - положение полюса второстепенной и дополнительной систем тройственного парагенезиса трещин. Выделены установленные морфогенетические типы разломов.

Fig. 3. Comparison of diagrams with the standard paragenesis of the second-rank fractures and fracturing in the zones of the normal fault (a), overthrust (б), left- ( 8 ) and right- (2) lateral strike-slip faults.

Poles of the main first-rank faults: 1 - strike-slip, 2 - thrust (overthrust), 3 - normal types; poles of the second-rank fractures (colous show fractures of different series): 4 - strike-slip fault, 5 - thrust (overthrust) fault, 6 - normal fault, 7 - strike-slip fault with overthrust component, 8 - strike-slip fault with normal component; $9-$ positions of poles of the secondary and additional systems of the triple paragenesis of fractures. Accepted solutions on the morphogenetic types are highlighted. 

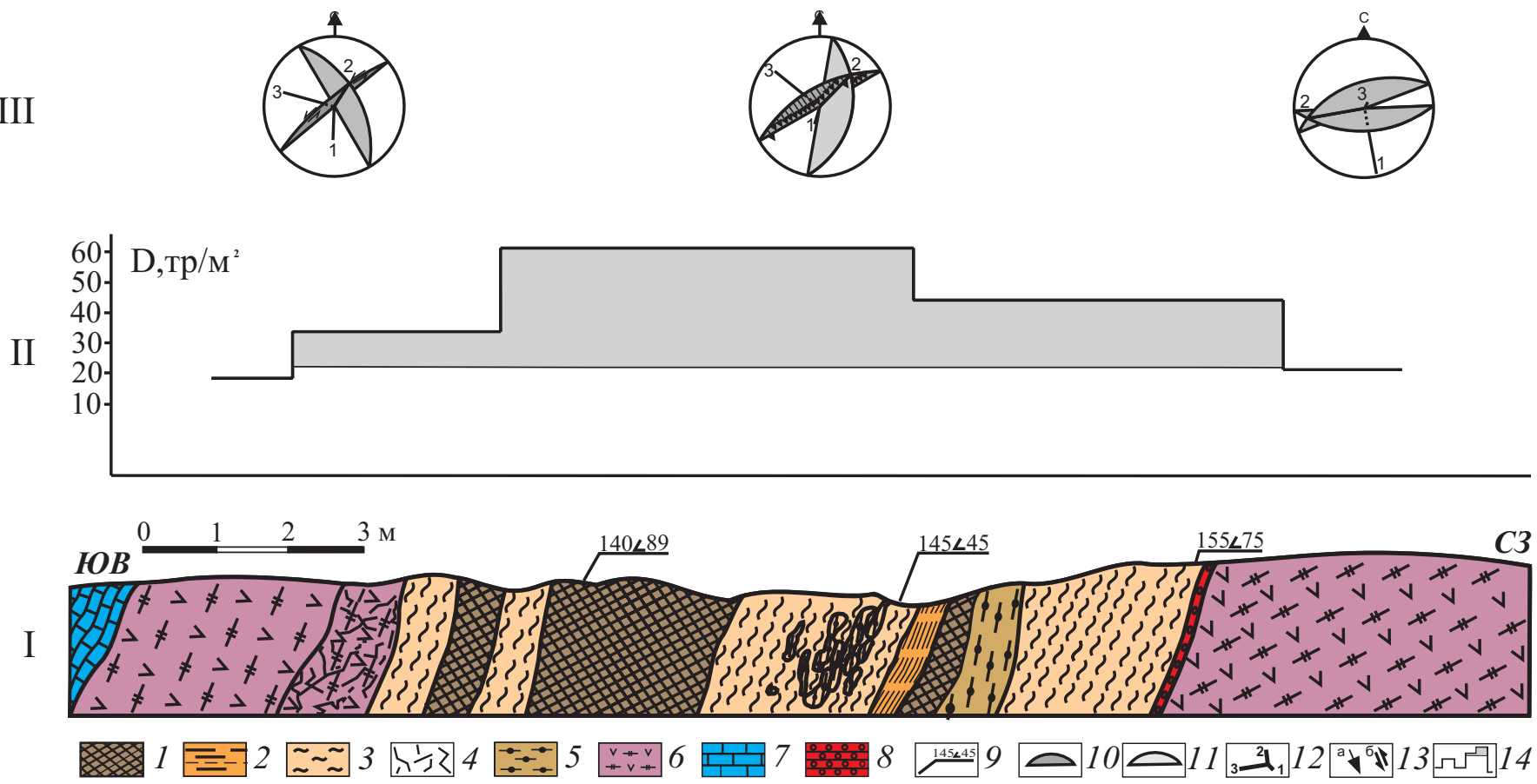

Рис. 4. Внутренняя структура и напряженное состояние разломной зоны на мысе Улирба.

I - геолого-структурный разрез, II - график изменения по разрезу плотности трещин (D, тp/м2), III - cтруктурные диаграммы, построенные в проекции верхней полусферы.

1-3 - тектонические изменения горных пород: 1 - дробление, 2 - рассланцевание, 3 - катаклаз и милонитизация; 4 - повышенная трещиноватость; 5-8 - горные породы: 5 - биотитовые гнейсы, 6 - амфиболовые гнейсы, 7 - мраморы; 8 - жила кварца; 9 - элементы залегания разломных зон (аз. падения и угол); 10-11 - плоскости разломной (темная заливка) и сопряженной (светлая заливка) с ней систем; 12 - оси главных нормальных напряжений сжатия (1), промежуточной (2) и растяжения (3); 13 - направление скольжения по плоскости разлома (а - субвертикальное, б - субгоризонтальное); 14 - на графике плотности трещин затемнены участки с повышенной трещиноватостью.

Fig. 4. The internal structure and the state of stresses of the fault zones at the Ulirba Cape.

I - geological and structural profile, II - fracture density (D, fractures per square metre) curve, III - structural diagrams reconstructed for the upper hemisphere projection.

1-3 - tectonically altered rocks: 1 - crushing, 2 - schistosity, 3 - cataclasis and mylonitization, 4 - high fracturing; 5 - 8 - rocks: 5 - biotite gneiss, 6 - amphibole gneiss, 7 - marble; 8 - quartz vein; 9 - dip azimuth and angles of fault zones; 10-11 - planes of the fault (dark) and conjugated (light) systems; 12 - axes of the main normal stresses of compression (1), transition (2) and extension (3); 13 - direction of sliding along the fault plane (a - sub-vertical, 6 - sub-horizontal); 14 - darker colour on the curve shows areas with high fracturing.

нормальных напряжений [Парфренов, 1984].

\section{ВНУТРЕННЯЯ СТРУКТУРА РАЗЛОМНЫХ ЗОН И ОРИЕНТАЦИЯ ОСЕЙ ПАЛЕОНАПРЯЖЕНИЙ}

На основе документации детальных участков были составлены геолого-структурные разрезы, отображающие особенности внутреннего строения разломных зон Приольхонья (рис. 4, I - 7, I). На разрезах хорошо видно, что зона разлома, выделенная по плотности трещиноватости (рис. 4, II - 7, II), представлена чередующимися областями развития различных тектонитов (катаклаз и милонитизация, дробление или рассланцевание горных пород), а также участками горных пород с повышенной трещиноватостью. В изученных разломных зонах часто наблюдается ожелезнение (лимонитизация) поверхностей трещин, а иногда кальцитизация, окварцевание и др. В основном это минералы, отложение которых происходит в приповерхностных условиях, но иногда в зонах разломов отмечаются структурновещественные преобразования, характерные для более глубинных уровней земной коры [Метаморфозм..., 2001]. Последнее свидетельствует о том, что для ряда разломов наблюдаются выведенные на поверхность корневые части.

Для каждой разломной зоны были реконструированы положение основного сместителя и парагенетически связанного с ним разрыва второго порядка, а также напряженное состояние (ориентация главных осей) при котором они образовались (рис. 4, III - 7, III). За пределами разломных зон напряженное состояние установлено по сопряженным сколам начального этапа разрушения горных пород ( $R$ и R' сколы). Всего для 47 массовых замеров трещиноватости было получено 54 решения ориентации осей палеонапряжений и для 28 разрывов разного ранга установлены типы подвижек на разных участках их зон. Большинство решений привязано к интервалам детальных разрезов, что позволяет охарактеризовать палеонапряжения в разломных зонах и за их пределами. Таким образом, был получен представительный фрактический материал для проведения статистического анализа и систематизации полей 

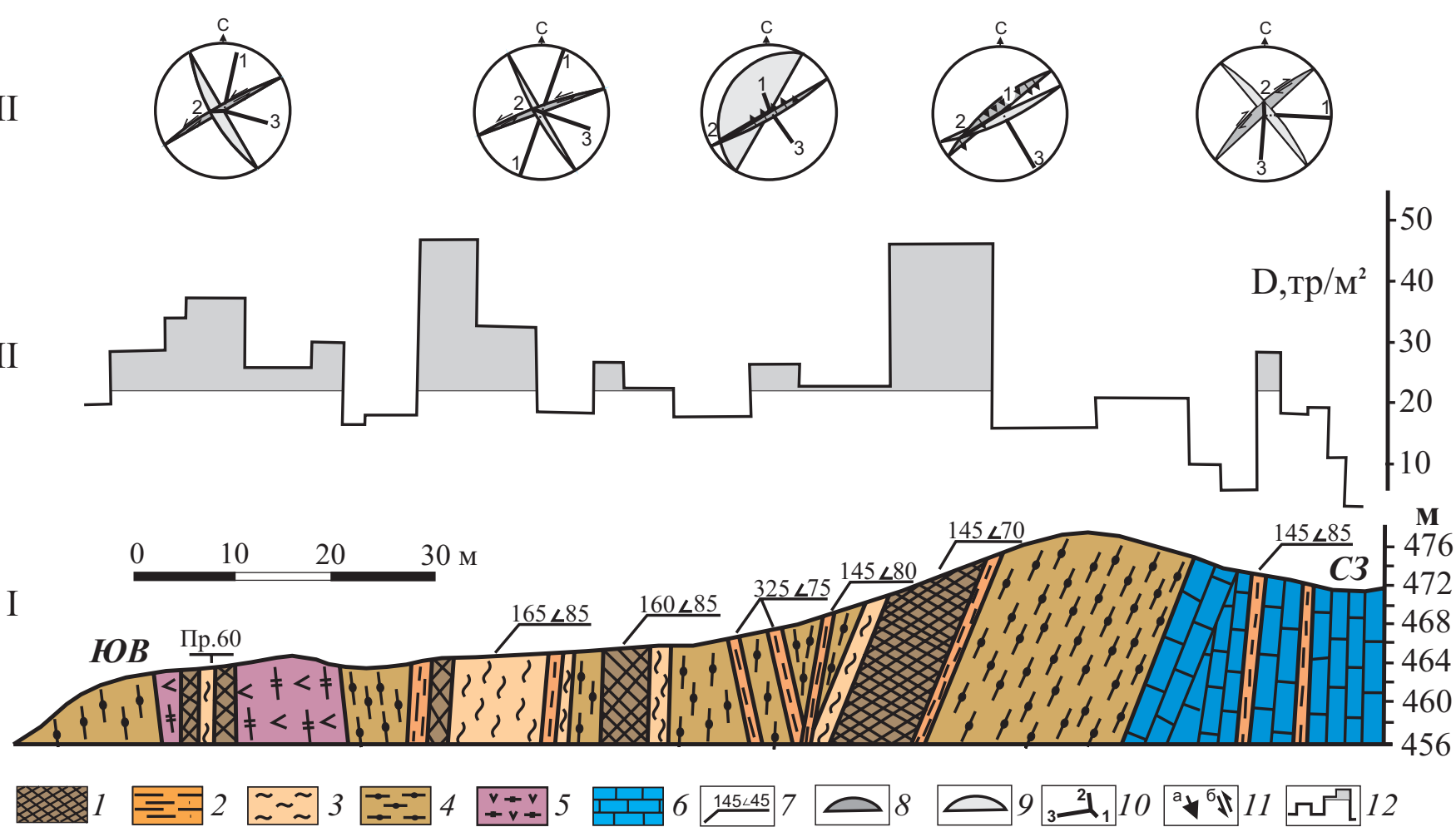

Рис. 5. Внутренняя структура и напряженное состояние разломных зон оконечности мыса Улирба.

I - геолого-структурный разрез, II - график изменения по разрезу плотности трещин, III - структурные диаграммы, построенные в проекции верхней полусферы.

1-3 - тектонические изменения горных пород: 1 - дробление, 2 - рассланцевание, 3 - катаклаз и милонитизация; 4-6 - горные породы: 4 - биотитовые гнейсы, 5 - амфиболовые гнейсы, 6 - мраморы; 7 - элементы залегания разломных зон (аз. падения и угол); 8-9 плоскости разломной (темная заливка) и сопряженной (светлая заливка) с ней систем; 10 - оси главных нормальных напряжений сжатия (1), промежуточной (2) и растяжения (3); 11 - направление скольжения по плоскости разлома (а - субвертикальное, б - субгоризонтальное); 12 - на графике плотности трещин затемнены участки с повышенной трещиноватостью.

Fig. 5. The internal structure and the state of stresses of the fault zones at the termination of the Ulirba Cape.

I - geological and structural profile, II - fracture density curve, III - structural diagrams reconstructed for the upper hemisphere projection.

1-3 - tectonically altered rocks: 1 - crushing, 2 - schistosity, 3 - cataclasis and mylonitization, 4-6 - rocks: 4 - biotite gneiss, 5 - amphibole gneiss, 6 - marble; 7 - dip azimuth and angles of fault zones; 8-9-planes of the fault (dark) and conjugated (light) systems; $10-$ axes of the main normal stresses of compression (1), transition (2) and extension (3); 11 - direction of sliding along the fault plane (a - sub-vertical, 6 sub-horizontal); 12 - darker colour on the curve shows areas with high fracturing.

напряжений по отношению к разноранговым разломам, имеющим северо-восточное простирание.

Так, зафиксированные на профиле разломы в $55 \%$ случаев имеют признаки сбросовых перемещений, в $27 \%$ - сдвиговых с левосторонней компонентой смещения, в $10 \%$ - взбросовых и только в $8 \%$ - сдвиговых перемещений с правосторонней компонентой. Внутренняя структура разломных зон состоит из вещественного наполнения (тектониты) и парагенетически связанной с разломом трещиноватости, которая нарушает сплошность «неизмененных» горных пород. Рассмотрим внутреннюю структуру зон разломов разных морфогенетических типов, зафиксированных в Приольхонье.

Внутренняя структура сбросов характеризуется следующими особенностями. В зонах отмечается асимметричное строение, при котором более раздробленно висячее крыло разлома. Кроме того, в зонах сбросов часто наблюдается наиболее интенсивная переработка горных пород (рис. 4, 7). При этом сбросовый тип подвижки установлен для наи- более крупных разломов района исследований.

Весьма распространенный морфогенетический тип разломов Приольхонья - сдвиги с левосторонней компонентой смещения - как правило, фриксируются вблизи крупных сбросов и характеризуются меньшей плотностью трещиноватости (рис. 4, 7). Часто зоны сдвигов с левосторонней компонентой смещения представлены повышенной трещиноватостью и дроблением, реже наблюдаются рассланцевание горных пород и катаклаз. Наиболее показательными являются зоны, изученные на мысе Улирба (рис. 5). Для них характерно достаточно симметричное строение, при котором катаклаз наблюдается в центральной части, а по мере удаления от центра интенсивность тектонической переработки горных пород уменьшается (дробление, повышенная трещиноватость).

Взбросы как самостоятельный морфогенетический тип разломов наблюдаются редко. В пределах детальных участков они не зафиксированы. Только на одном из участков, за пределами разломных зон, 
III
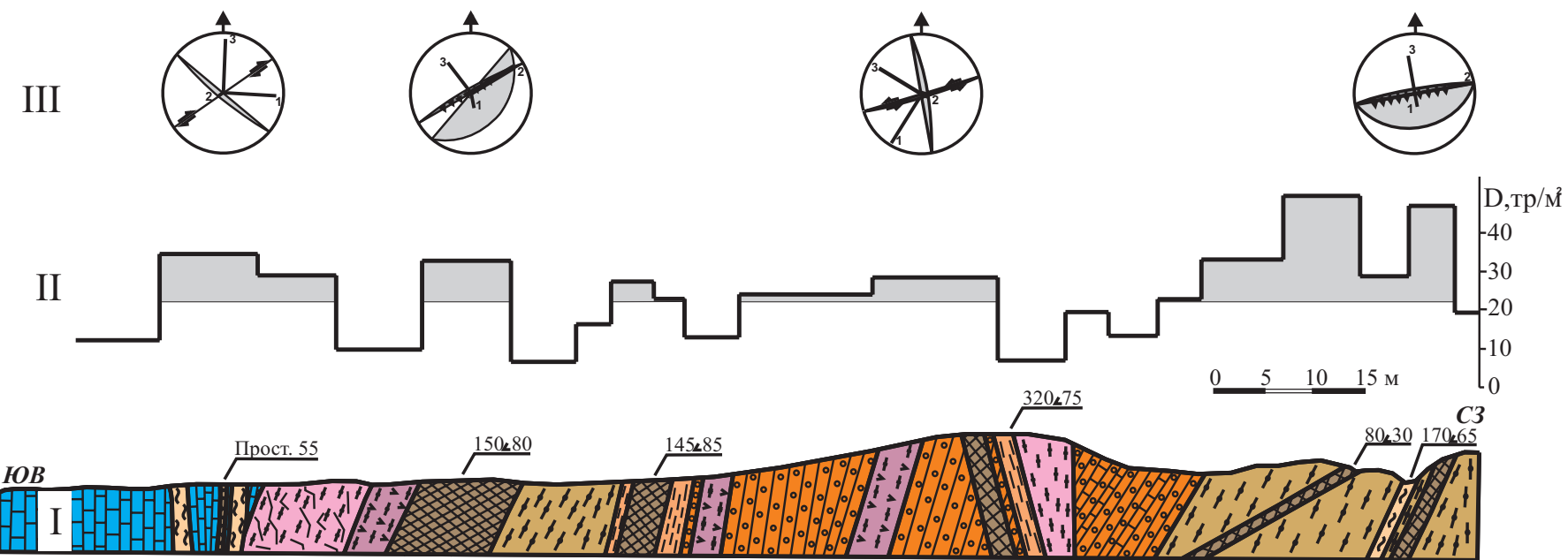

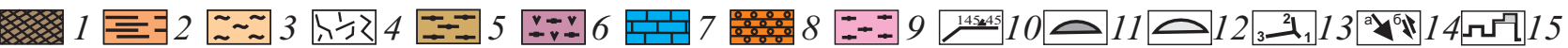

Рис. 6. Внутренняя структура и поля напряжений в разломных зонах юго-восточного побережья залива Куркут.

I - геолого-структурный разрез, II - график изменения по разрезу плотности трещин (D, Tp/M $\left.{ }^{2}\right)$, III - структурные диаграммы, построенные в проекции верхней полусферы.

1-4 - тектонические изменения горных пород: 1 - дробление, 2 - рассланцевание, 3 - катаклаз и милонитизация, 4 - повышенная трещиноватость; 5-9 - горные породы: 5 - биотитовые гнейсы, 6 - амфиболовые гнейсы, 7 - мраморы, 8 - кварциты, 9 - пегматиты; 10 - элементы залегания разломных зон (аз. падения и угол); 11-12 - плоскости разломной (темная заливка) и сопряженной (светлая заливка) с ней систем; 13 - оси главных нормальных напряжений сжатия (1), промежуточного (2) и растяжения (3); 14 - направление скольжения по плоскости разлома (а - субвертикальное, б - субгоризонтальное); 15 - на графике плотности трещин затемнены участки с повышенной трещиноватостью.

Fig. 6. The internal structure and the state of stresses of the fault zones at the south-eastern shoreline of the Kurkut Bay.

I - geological and structural profile, II - fracture density curve, III - structural diagrams reconstructed for the upper hemisphere projection.

1-4 - tectonically altered rocks: 1 - crushing, 2 - schistosity, 3 - cataclasis and mylonitization, 4 - high fracturing; 5-9 - rocks: 5- biotite gneiss, 6 -amphibole gneiss, 7 - marble, 8 - quartzite, 9 - pegmatite; 10 - dip azimuth and angles of fault zones; 11-12-planes of the fault (dark) and conjugated (light) systems; 13 - axes of the main normal stresses of compression (1), transition (2) and extension (3); 14 - direction of sliding along the fault plane (a - sub-vertical, 6 - sub-horizontal); 15 - darker colour on the curve shows areas with high fracturing.

в слабонарушенном блоке восстанавливается напряженное состояние сжатия (рис. 7). Кроме того, парагенезис взброса иногда наблюдается в зонах сбросов, но его слабая выраженность на диаграммах свидетельствует о переработке внутренней структуры этих разломов в последующие тектонические эпохи.

Сдвиги с правосторонней компонентой смещения крыльев встречаются редко и характеризуются узкими «прослоями» тектонитов в пределах относительно широких областей повышенной трещиноватости (рис. 5,6 ). Низкая частота встречаемости этих разломов позволяет предположить, что они либо образовались на самых ранних этапах тектонической активности региона, либо являются не основными структурами выявленных этапов тектогенеза, а сопутствующими им разрывами более низкого порядка.

Однако простирание установленных разломов колеблется в небольших пределах - от $43^{\circ}$ до $80^{\circ}$. При этом сбросы тяготеют к интервалу 50-60, левосторонние сдвиги - 60-70 ронние сдвиги имеют простирание $60^{\circ}$. Таким образом, из парагенетических сочетаний разрывов возможна лишь взаимосвязь сбросов с простиранием $\sim 50^{\circ}$ в качестве разрывов первого порядка и левосторонних сдвигов - $70^{\circ}$ как разрывов второго по- рядка по отношению к сбросам. В целом, разломы разных морфогенетических типов развивались при напряженных состояниях, значительно отличающихся по ориентировке осей, что, вероятнее всего, свидетельствует об их принадлежности к различным этапам тектогенеза.

Важным вопросом изучения напряженного состояния, в котором образовались разломы, является время формирования тектонической трещиноватости. К сожалению, в пределах профиля кайнозойские осадки встречены только в одном месте. Они представлены суглинками с примесью гравия, которые залегают горизонтально и частично налегают на гранитогнейсы, расположенные севернее. Разлом в этой точке наблюдения не зафиксирован, о чем свидетельствует низкая (13-15 тр/м²) плотность трещин в коренных породах. Кроме того, о расположении данного обнажения вне разломных зон свидетельствует и трещиноватость гранитогнейсов, формирование которой происходило в обстановке субгоризонтального сжатия с погружением оси $340 \angle 20^{\circ}$. При этом в кайнозойских суглинках восстановлены обстановки растяжения и сдвига с левосторонней компонентой смещения, характерные для кайнозойского этапа развития региона.

Результаты детальных исследований внутренней структуры разломных зон Приольхонья и напря- 
III
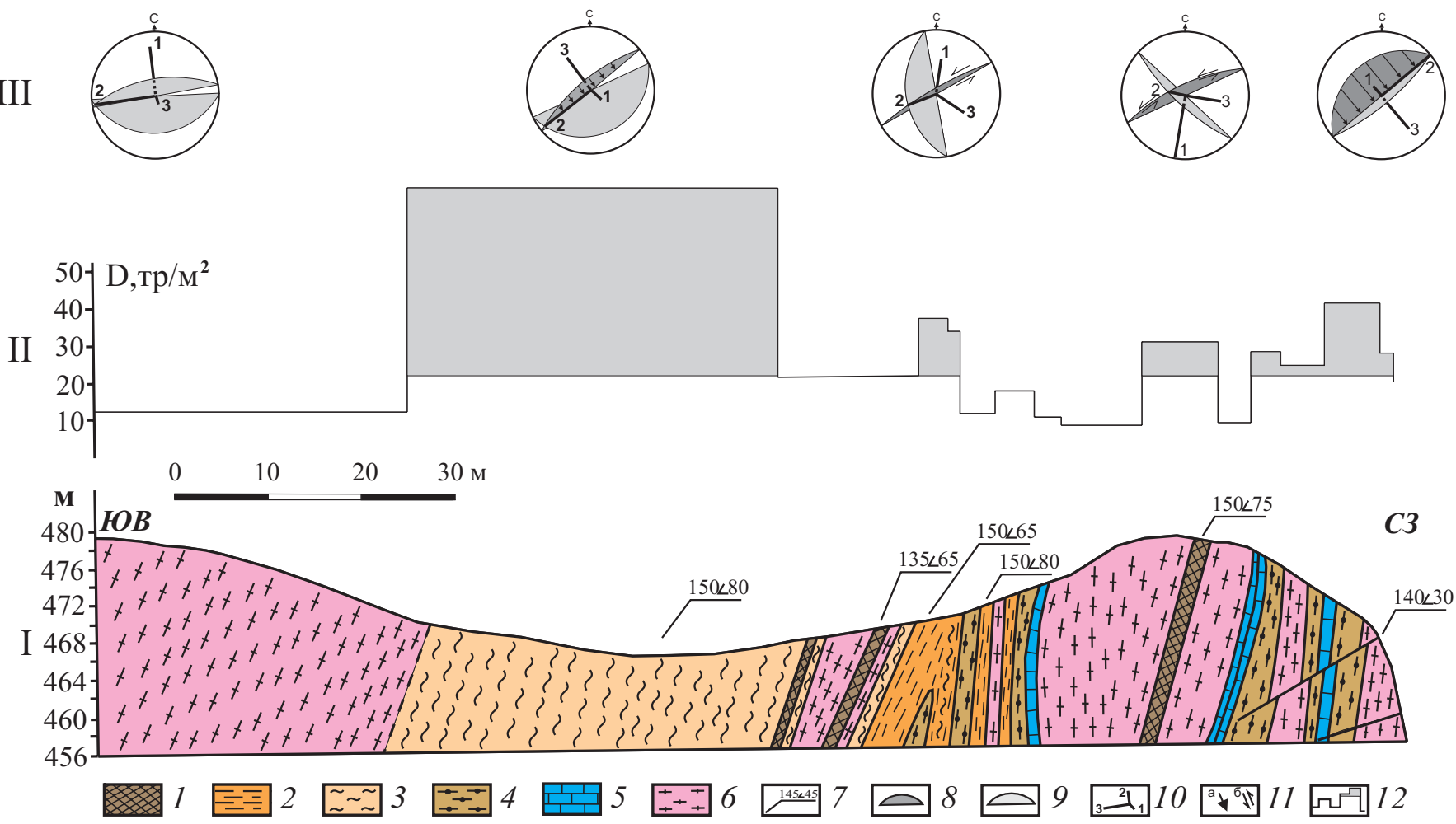

Рис. 7. Внутренняя структура и напряженное состояние разломных зон юго-восточного побережья залива Куркут (на продолжении к ЮВ от рис. 5).

I - геолого-структурный разрез, II - график изменения по разрезу плотности трещин, III - структурные диаграммы, построенные в проекции верхней полусферы.

1-3 - тектонические изменения горных пород: 1 - дробление, 2 - рассланцевание, 3 - катаклаз и милонитизация; 4-6 - горные породы: 4 - биотитовые гнейсы, 5 - мраморы, 6 - пегматиты; 7 - элементы залегания разломных зон (аз. падения и угол); 8-9 - плоскости разломной (темная заливка) и сопряженной (светлая заливка) с ней систем; 10 - оси главных нормальных напряжений сжатия (1), промежуточной (2) и растяжения (3); 11 - направление скольжения по плоскости разлома (а - субвертикальное, б - субгоризонтальное); 12 - на графике плотности трещин затемнены участки с повышенной трещиноватостью.

Fig. 7. The internal structure and the state of stresses of the fault zones at at the south-eastern shoreline of the Kurkut Bay (Fig. 5 continued in the south-eastern direction).

I - geological and structural profile, II - fracture density curve, III - structural diagrams reconstructed for the upper hemisphere projection.

1-3 - tectonically altered rocks: 1 - crushing, 2 - schistosity, 3 - cataclasis and mylonitization, 4-6 - rocks: 4 - biotite gneiss, 5 - marble; 6 - pegmatite; 7 - dip azimuth and angles of fault zones; $8-9$ - planes of the fault (dark) and conjugated (light) systems; $10-$ axes of the main normal stresses of compression (1), transition (2) and extension (3); 11 - direction of sliding along the fault plane (a - sub-vertical, 6 - subhorizontal); 12 - darker colour on the curve shows areas with high fracturing.

женного состояния верхней части земной коры, полученные нами, отражают эволюцию напряженного состояния региона.

\section{ОБ ЭВОЛЮЦИИ НАПРЯЖЕННОГО СОСТОЯНИЯ ВЕРХНЕЙ КОРЫ БАЙКАЛЬСКОГО РИФТА}

Выше отмечено, что в геологической истории Прибайкалья отражены поля напряжений различных тектонических этапов. Разнообразие ориентации осей напряжений локальных решений при этом зависит как от наложения разновозрастных полей, так и от простирания разломов, их ранга и условий взаимодействия дизъюнктивов (узлы сочленения). Проведенные исследования были нацелены на реконструкцию напряженного состояния, при котором активно развивались разломы северо-восточной ориентации, с достаточно небольшим диапазоном азимутов простирания - 43-80 (медиана 60).
Наиболее встречаемыми, как и следовало ожидать, являются напряженные состояния сдвига и растяжения (рис. 8), так как большинство изученных разломов относятся к сбросам, значительно реже наблюдаются сдвиги и сбросо-сдвиги. Среди сдвигов резко преобладают дизъюнктивы с левосторонней компонентой смещения. Надвиги и взбросы в пределах изученного профиля имеют весьма незначительное распространение, потому что переработаны сдвиговыми и сбросовыми смещениями на неотектоническом этапе развития региона. В ходе кайнозойской активизации по ослабленным зонам разрывных нарушений интенсивно проявились наиболее молодые смещения, особенно сбросовые. Данный вывод подтверждается характером трещиноватости горных пород Приольхонья, когда восстановленные сдвиговые поля напряжений располагаются на периферии крупных разломных зон сбросового кинематического типа, а обстановки 


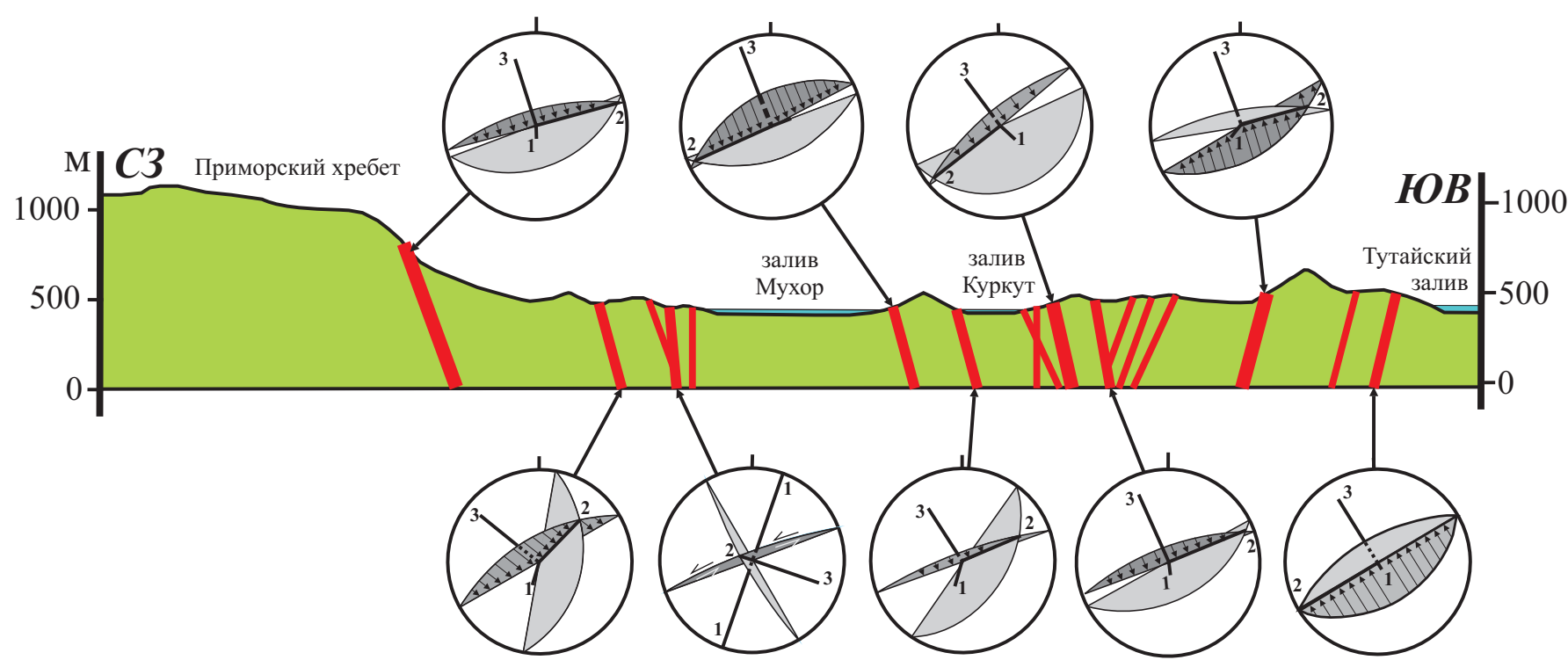

Рис. 8. Положение основных разломов Приольхонья на поперечном геоморфологическом профиле и напряженное состояние верхней коры при их формировании.

Толщиной линии показана разная мощность разломных зон: $>40$ м, 20-40 м, <20 м.

Fig. 8. The main faults of the Priolkhonie at the transverse geomorphological, and the state of stresses of the upper crust during formation of such faults.

Three thicknesses of the line show fault zone thicknesses as follows: $>40 \mathrm{~m}, 20-40 \mathrm{~m},<20 \mathrm{~m}$.

сжатия - за их пределами. Кроме того, структурный парагенезис взбросов может быть обнаружен в границах разломных зон сбросового типа, но проявлен он хуже. Это свидетельствует об активизации данных разломов при кайнозойском рифтогенезе и частичном использовании трещиноватости их зон, так как совпала ориентировка (СЗ-ЮВ) сжатия и более позднего растяжения. При этом существовавшие разрывы поменяли знак смещения на обратный и частично перестроили свою внутреннюю структуру [Семинский, 2003]. Исследования показали, что, чем крупнее активизированные разломы, тем менее проявлены в их внутренней структуре элементы более раннего сжатия.

Выше уже было отмечено, что напряженное состояние сжатия с ориентацией оси СЗ-ЮВ как самостоятельный тип чаще фриксируется в горных породах за пределами изученных разломных зон, а собственно взбросы встречаются достаточно редко. Этот фракт свидетельствует о том, что в пределах района исследований этап сжатия земной коры с ориентацией оси СЗ-ЮВ является наиболее древним.

Следует рассмотреть подробнее модели эволюции напряженного состояния Прибайкалья в мезокайнозое, в которых присутствуют отличающиеся от установленных нами ориентации осей палеонапряжений [Петров и др., 2008; Лунина и др., 2009]. В приведенных работах не рассматриваются иерархические свойства поля напряжений. Однако на рис. 2 показано, что в процессе формирования зоны разлома (в качестве примера приведен парагенезис зоны сброса) происходит переиндексация осей напряжений, в результате которой наблюдаются поля напряжений более низкого порядка. Таким образом, растяжение и сжатие северо-восточной ориентации, продольные по отношению к рифтообразующим разломам, не являются результатом смены регионального поля напряжений. Это специфика формирования ортогональных региональному растяжению разломов при рифтогенезе. Поэтому некоторые реконструкции напряженного состояния, по нашему мнению, в большей степени отражают иерархические свойства поля напряжений, а не смену региональных напряжений во времени. Кроме того, развитие разломной зоны с поэтапным формированием сколов трех серий и переиндексацией осей главных напряжений сопровождается эволюцией локального напряженного состояния в пределах дизъюнктива.

Вопрос о возрасте проявления режимов с различными типами полей напряжений является сложным. Сжатие земной коры, вероятнее всего, было полихронное. Так, В.К. Александров выделяет в Прибайкалье надвиги трех возрастных групп: дорифейские, раннепалеозойские и мезозойские. При этом главнейшей на территории западной окраины Байкальской горной области называется раннепалеозойская эпоха надвиговой тектоники [Александров, 1990]. Кроме того, мы не исключаем возможности достаточно масштабного сжатия в кайнозое (например, миоцен-плиоценовые надвиги в Тункинских гольцах [Ружич и др., 1972]), однако в трещиноватости рыхлых отложений Приольхонья оно не выявлено.

Таким образом, относительная последовательность смены полей напряжений в данном регионе выглядит следующим образом: сжатие СЗ-ЮВ ори- 
ентации, сдвиговое поле с С-СВ простиранием оси сжатия и 3-С3 - оси растяжения, растяжение С3ЮВ ориентации.

\section{ЗАКЛЮЧЕНИЕ}

Проведенные исследования подтвердили выявленные ранее закономерности тектонического строения Приольхонья и детализировали внутреннюю структуру разноранговых разломных зон, а также позволили реконструировать напряженное состояние, в котором они образовались или активизировались.

Внутренняя структура большинства разломных зон имеет сложное строение, при котором разлом представлен чередованием областей развития различных тектонитов, слагающих основной сместитель дизъюнктива, а на периферии - повышенной трещиноватостью горных пород. Наблюдаемая в зоне разлома внутренняя структура отражает наложенный характер деформаций в их пределах, который связан как с динамикой формирования дизъюнктива на определенном временном этапе, так и с его неоднократной активизацией при смене регионального поля напряжений. В таких условиях реконструкция напряженного состояния по трещиноватости горных пород затруднена. Однако детальность исследований и использование комплекса тектонофизических методов, при ведущей роли структурнопарагенетического анализа разрывов второго порядка и трещиноватости вблизи разломных сместителей, позволили установить особенности напряженного состояния верхней части земной коры.

Специфика напряженно-деформированного состояния в разломных зонах Приольхонья и за их пределами подтверждает представление о том, что в Прибайкалье происходила эволюция напряженного состояния верхней коры от сжатия, через сдвиговое поле, к растяжению. При этом сдвиги с левосторонней компонентой смещения и сбросы развивались в кайнозойское время. Для более детальной хронологии напряженного состояния верхней коры региона необходима представительная статистика об ориентации осей в разновозрастных датированных осадках и вулканических образованиях кайнозоя. На данном этапе исследований можно лишь предположить, что сдвиговое поле напряжений с С-СВ простиранием оси сжатия и 3-С3 - оси растяжения имеет миоцен-плиоценовый возраст, так как ориентация оси сжатия совпадает с направлением таковой при формировании надвигов в Тункинских гольцах [Ружич и др., 1972]. При этом сдвиговый характер деформации горных пород в Западном Прибайкалье возник ввиду структурно-вещественной неоднородности, обусловленной наличием здесь дислокаций северо-восточной ориентации.

Таким образом, особенности внутренней структуры разломных зон и специфика полей напряжений обусловлены структурно-вещественной неоднородностью, иерархическими свойствами и эволюцией напряженного состояния верхней части земной коры Приольхонья.

\section{БЛАГОДАРНОСТИ}

Автор выражает глубокую признательность доктору геол.-мин. наук К.Ж. Семинскому, осуществляющему руководство комплексными исследованиями разломных зон Прибайкалья, а также сотрудникам лаборатории А.А. Боброву, Ю.П. Бурзуновой, Е.И. Когуту за помощь при проведении работ и предоставленные материалы.

Работа выполнена при поддержке РФФИ (проект № 08-05-98062), программы СО РАН ОН3-7 (проект № 6) и ФЦП (госконтракт 02.740.11.0446).

\section{ЛИтеРАТУРА}

Александров В.К. Надвиговые и шарьяжные структуры Прибайкалья. - Новосибирск: Наука, 1990. - 103 с.

Гзовский М.В. Основные вопросы тектонофизики и тектоника Байджансайского антиклинория. Ч. III-IV. - М.: Изд-во АН СССР, 1963. - 544 c.

Данилович В.Н. Метод поясов в исследовании трещиноватости, связанной с разрывными смещениями (методическое руководство). - Иркутск: ИПИ, 1961. - 47 с.

Лунина О.В., Гладков А.С., Неведрова Н.Н. Рифртовые впадины Прибайкалья: тектоническое строение и история развития. Новосибирск: Академическое изд-во «Гео», 2009. - 316 с.

Мац В.Д., Уфимцев Г.Ф., Мандельбаум М.М., Алакшин А.М., Поспеев А.В., Шимараев М.Н., Хлыстов О.М. Кайнозой Байкальской рифтовой впадины: строение и геологическая история. - Новосибирск: Изд-во СО РАН, филиал «Гео», 2001. $252 \mathrm{c}$.

Метаморфизм и тектоника: Учебное пособие / Е.В. Скляров и др. - М.: «Интермет Инжиниринг», 2001. - 216 с.

Мишарина Л.А., Солоненко Н.В. Механизм очагов и поле тектонических напряжений // Сейсмическое районирование Восточной Сибири и его геолого-геофизические основы. - Новосибирск: Наука, 1977. - С. 71-78.

Парфеееец А.В., Саньков В.А., Мирошниченко А.И., Лухнев А.В. Эволюция напряженного состояния земной коры МонголоБайкальского подвижного пояса // Тихоокеанская геология. 2002. - T. 21, № 1. - C. 14-28.

Парфренов В.Д. К методике тектонофизического анализа геологических структур // Геотектоника. - 1984. - №1. - С. 60-72.

Петров В.А., Мострюков А.О., Васильев Н.Ю. Структура современного поля напряжений мезозойско-кайнозойского цикла деформации Байкальской рифтовой зоны // Геофизические исследования. - 2008. - Т. 9, № 3. - С. 39-61.

Плешанов С.П., Чернов Ю.А. О генетической связи кайнозойских разрывных нарушений западного Прибайкалья с разломами докембрийского заложения // Вопросы геологии Прибайкалья и Забайкалья. - Чита, 1971. - С. 51-54.

Ружич В.В., Шерман С.И., Тарасевич С.И. Новые данные о надвигах в юго-западной части Байкальской рифтовой зоны // Доклады АН СССР. - 1972. - Т. 205, № 4. - С. 916-920.

Семинский К.Ж. Внутренняя структура континентальных разломных зон. Тектонофизический аспект. - Новосибирск: Изд-во СО РАН, Филиал «Гео», 2003. - 244 с.

Семинский К.Ж., Гладков А.С., Лунина О.В., Тугарина М.А. Внутренняя структура континентальных разломных зон. Прикладной аспект. - Новосибирск: Изд-во СО РАН, филиал «Гео», 2005. -293 c.

Семинский К.Ж., Кожевников Н.О., Черемных А.В., Бобров А.А., Оленченко В.В., Авгулевич Д.Л. Структура разломных зон Приольхонья (Байкальский рифт) по данным полевой тектоно- и геофизики // Известия Сибирского отделения секции наук о Земле РАЕН. Геология, поиски и разведка рудных месторождений. - 2008. - Вып. 7 (33). - С. 111-124.

Шерман С.И. Физические закономерности развития разломов земной коры. - Новосибирск: Наука, 1977. - 102 с.

Cheremnykh A.V. Structure and stress field of faulted crust on the eastern side of Lake Baikal // Russian geology and geophysics. 2006. - V. 47, № 2. - P. 257-264.

Fedorovsky V.S. Dome tectonics in the Caledonian collision system of Western Cisbaikalia // Geotectonics. - 1997. - V. 31, № 6. - P. 483-497. 
Lunina O.V., Gladkov A.S., Cheremnykh A.V. Fracturing in the Primorsky fault zone (Baikal rift system) // Russian geology and geophysics. - 2002. - V. 43, № 5. - P. 446-455.

Mel'nikova V.I., Radziminovich N.A. Parameters of seismotectonic Deformations of the Earth's crust in the Baikal rift zone based on seismological data // Doklady Earth Sciences. - 2007. - V. 416, № 7. - P. 1137-1139.
San'kov V.A., Miroshnitchenko A.I., Levi K.G., Lukhnev A.V., Melnikov A.l., Delvaux D. Cenozoic stress field evolution in the Baikal rift zone // Bull. Centre Rech. Elf Explor. Prod. - 1997. - V. 21, № 2. - P. 435-455.

Seminsky K.Zh., Burzunova Yu.P. Interpretation of chaotic jointing near fault planes: a new approach // Russian geology and geophysics. - 2007. - V. 48, № 3. - P. 257-266.

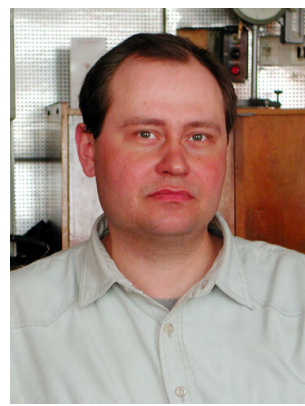

Черемных Александр Викторович, канд. геол.-мин. наук, с. н. с.

Зетитут земноЙ коры СО РАН

664033, Иркутск, ул. Лермонтова, 128, Россия

Тел. 89501404851; e-mail: cherem@crust.irk.ru

Cheremnykh Alexander V., Candidate of Geology and Mineralogy, Senior Researcher

Institute of the Earth's Crust, Siberian Branch of RAS

664033, Irkutsk, Lermontov street, 128, Russia

Tel. 89501404851; e-mail: cherem@crust.irk.ru 